\title{
The Mechanism of Prevention and Treatment of Maxing Shigan Decoction on Pulmonary Heart Injury Caused by Novel Coronavirus Pneumonia
}

\section{Dongling Liu}

Gansu University of Chinese Medicine, Lanzhou 730000, China 2Provincial-Level Key Laboratory for Molecular Medicine of Major Diseases and The Prevention and Treatment with Traditional Chinese Medicine Research in Gansu Colleges and University, Lanzhou, Gansu 730000, China Jing Su

Gansu University of Chinese Medicine, Lanzhou 730000, China 2Provincial-Level Key Laboratory for Molecular Medicine of Major Diseases and The Prevention and Treatment with Traditional Chinese Medicine Research in Gansu Colleges and University, Lanzhou, Gansu 730000, China

\section{Wenqian Hou}

Gansu University of Chinese Medicine, Lanzhou 730000, China 2Provincial-Level Key Laboratory for Molecular Medicine of Major Diseases and The Prevention and Treatment with Traditional Chinese Medicine Research in Gansu Colleges and University, Lanzhou, Gansu 730000, China

\section{Weiyu Ren}

Gansu University of Chinese Medicine, Lanzhou 730000, China 2Provincial-Level Key Laboratory for Molecular Medicine of Major Diseases and The Prevention and Treatment with Traditional Chinese Medicine Research in Gansu Colleges and University, Lanzhou, Gansu 730000, China

\section{Yijun Zheng}

Gansu University of Chinese Medicine, Lanzhou 730000, China 2Provincial-Level Key Laboratory for Molecular Medicine of Major Diseases and The Prevention and Treatment with Traditional Chinese Medicine Research in Gansu Colleges and University, Lanzhou, Gansu 730000, China

\section{Yanmei Ning}

Gansu University of Chinese Medicine, Lanzhou 730000, China 2Provincial-Level Key Laboratory for Molecular Medicine of Major Diseases and The Prevention and Treatment with Traditional Chinese Medicine Research in Gansu Colleges and University, Lanzhou, Gansu 730000, China

\section{Xiaojie Jin}

Gansu University of Chinese Medicine, Lanzhou 730000, China 2Provincial-Level Key Laboratory for Molecular Medicine of Major Diseases and The Prevention and Treatment with Traditional Chinese Medicine Research in Gansu Colleges and University, Lanzhou, Gansu 730000, China

\section{Yongqi Liu ( $D$ liuyongqi73@163.com )}

Gansu University of Chinese Medicine, Lanzhou 730000, China 2Provincial-Level Key Laboratory for Molecular Medicine of Major Diseases and The Prevention and Treatment with Traditional Chinese 


\section{Methodology}

Keywords: Maxing Shigan Decoction, COVID-19, Lung injury, Myocardial injury, Network pharmacology, Molecular docking

Posted Date: August 4th, 2020

DOI: https://doi.org/10.21203/rs.3.rs-44174/v1

License: (c) (1) This work is licensed under a Creative Commons Attribution 4.0 International License. Read Full License 


\section{Abstract \\ Background}

To explore the mechanism of Maxing Shigan Decoction in the treatment of myocardial injury and lung injury through network pharmacology and molecular docking technology.

\section{Methods}

In Traditional Chinese Medicine Systems Pharmacology Database and Analysis Platform (TCMSP), a Bioinformatics Analysis Tool for Molecular mechANism of Traditional Chinese Medicine (BATMAN-TCM) and the Comparative Toxicogenomics Database, National Center for Biotechnology Information database, Online Mendelian Inheritance in Man database, the compounds and targets of each drug in Maxing Shigan Decoction and the targets of "acute lung intervention" and "myocardial injury" diseases were searched. Gene Ontology (GO) enrichment analysis and Kyoto Encyclopedia of Genes and Genomes (KEGG) enrichment analysis were performed by the DAVID database. GOLD 5.1 was used for molecular docking.

\section{Results}

Maxing Shigan Decoction includes 327 compounds and 2722 targets, including 30 key targets. 2125 items were obtained by GO enrichment analysis, including 2047 items of Biological Process, 28 items of Cell Composition and 50 items of Molecular Function. The KEGG pathway was enriched to obtain 149 pathways. The results of molecular docking showed that Gancaonin $\mathrm{H}$ and Licorice Glycoside E were well combined with Angiotensin-Converting Enzyme 2-A (ACE2-A) and Angiotensin-Converting Enzyme 2-B (ACE2-B), respectively, and Licorice was well combined with Granulocyte-Macrophage Colony Stimulating Factor (GM-CSF) and Interleukin 6 (IL-6). Supraene is an active compound of Ephedra. It has good binding with ACE2-A, ACE2-B, GM-CSF and IL-6, respectively. (6Z, 10E, 14E, 18E)-2, 6, 10, 15, 19, 23 hexamethyletracosa-2, 6, 10,14, 18, 22- hexaene are the active compounds of Almond, which are well combined with ACE2-A, ACE2-B, GM-CSF and IL-6.

\section{Conclusion}

Maxing Shigan Decoction may act on ACE2, GM-CSF and IL-6 targets through the active compounds Supraene of Ephedra, and Almond (6Z, 10E, 14E, 18E)-2, 6, 10, 15, 19, 23-hexamethyletracosa-2, 6, 10, 14, 18, 22-hexaene. Gancainin H and licorice Glycide $E$ are the active compounds of Licorice, act on A and B sites of ACE2 respectively, and Glycyrin acts on GM-CSF and IL- 6 targets, coordinating multiple signal pathways to play anti-inflammatory and antiviral roles to prevent and treat lung and heart injury caused by Severe Acute Respiratory Syndrome Coronavirus 2 (SARS-CoV-2). 


\section{Introduction}

Novel coronavirus pneumonia (COVID-19) is caused by SARS-CoV-2 infection. Fever, fatigue and dry cough are the main manifestations [1], which are highly infectious and epidemic. According to imaging data, the lung is the main target organ of SARS-CoV-2 invasion [2], the computer tomography images of patients with COVID-19 have the characteristics of double lower lung, peripheral distribution, multiple lesions, ground glass shadow, solid shadow and grid strip shadow. With the progress of the course of disease, the density of lesions increases, grid strip shadow increases, and the recovery period of lesions becomes light or left local fibrosis [3]. In addition to the typical respiratory system performance, COVID-19 patients also have the occurrence of myocardial injury [4-6], mainly including palpitation, chest distress and other symptoms, as well as changes in electrocardiogram, myocardial enzyme spectrum and cardiac function. It is suggested that pulmonary heart injury is an important complication of COVID-19.

The results showed that both SARS-CoV-2 and Severe Acute Respiratory Syndrome Coronavirus infected epithelial cells with ACE2 as the receptor [7]. Most of the expression of ACE2 in the lung was similar to that of type II alveolar cells, and the large expression of ACE2 in type II alveolar cells may lead to lung injury in patients with COVID-19 [8]. When the virus invades the body, it can activate pathogenic $T$ cells and release pro-inflammatory factors including GM-CSF and IL-6. GM-CSF further activated Cluster of Differentiation $14^{+}$, Cluster of Differentiation $16^{+}$inflammatory monocytes, thus releasing more IL- 6 and other inflammatory factors, forming an inflammatory storm. In a short period of time, it causes serious pathological damage to tissues and organs, and eventually leads to multiple organ failure and even death [9]. The COVID-19 is a key factor inducing IL-6 inflammatory storm. Therefore, novel coronavirus pneumonia can be prevented from being further aggravated by inhibiting the expression of IL-6, which can theoretically prevent the occurrence of inflammatory storm.

Maxing Shigan Decoction was first published in Treatise on Febrile Diseases. It is a classic prescription for treating lung diseases. It is composed of Ephedra, Almond, Gypsum and Licorice. It is commonly used in the treatment of common cold, upper respiratory tract infection, acute bronchitis, pneumonia, bronchial asthma, measles with pneumonia and other diseases. The novel coronavirus pneumonia was used for the treatment of mild and normal type. Through the treatment of 40 cases of new-type coronavirus pneumonia, the combination of Chinese medicine and Maxing Shigan Decoction can significantly reduce the levels of IL- 6 and high sensitivity C Reactive Protein (CRP), and contribute to the control of new crown pneumonia and systemic inflammation $[10,11]$. The novel coronavirus pneumonia can be significantly improved by the treatment of Maxing Shigan Decoction.

Therefore, in this paper, network pharmacology and molecular docking technology are used to predict the intervention effect and mechanism of Maxing Shigan Decoction on the lung and heart injury caused by COVID-19, in order to provide scientific basis for its reasonable and effective application in related diseases.

\section{Methods}




\subsection{Construction of Return Network}

According to the statistics of the meridian tropism information of each Chinese medicine, the network of meridian tropism was constructed by using the software of Cytoscape 3.7.2.

\subsection{Screening of Active Compounds and Targets}

The keywords of Ephedra, Almond, Gypsum and Licorice were retrieved through TCMSP database and BATMAN-TCM database respectively. Seting the Oral Bioavailability $(O B) \geq 30 \%$ and Drug Like $(D L) \geq$ 0.18 in TCMSP database. The information of related active compounds was obtained by sorting. Score off $>20$ and $\mathrm{P}<0.01$ were set in BATMAN-TCM database to get the information of related compounds and targets. Then, the information of compound and target of Maxing Shigan Decoction was obtained by sorting out the information of compound from two databases.

\subsection{Maxing Shigan Decoction-Screening of Common Target of Disease}

Key words "Acute lung injury" and "injury" were searched in The Comparative Toxicogenomics Database, National Center for Biotechnology Information database, Online Mendelian Inheritance in Man database to find the disease targets. Finally, the target points of Maxing Shigan Decoction compound, acute lung injury and myocardial injury were intersected to get the common target points, which were visualized in omicshare online mapping software.

\subsection{Key Targets Selection}

Import the target from 1.3 into the string database, limit the species to "Homo sapiens", download the TSV file, and draw the histogram of the first 30 target degree values.

\subsection{Gene Enrichment Analysis}

The common targets were imported into the David database, and select the gene identifier "OFFICIAL_GENE_SYMBOL", the selection of gene species and background is "Homo sapiens", and the threshold is set to $P<0.05$. GO bioaccumulation analysis and KEGG pathway analysis are carried out.

\subsection{Molecular Docking of the Active Components of Maxing Shigan Decoction with ACE2, IL-6 and GM-CSF}


All the active molecular targets of Ephedra, Licorice and Almond screened by ADME were docking with ACE2, IL-6 and GM-CSF. The X-ray crystal structures of ACE2 (PDB ID: 6m18), IL-6 (PDB ID: 1p9m) and GM-CSF (PDB ID: 5c7x) were downloaded from the RCSB Protein Data Bank database. The docking experiment of protein molecular ligand complex was completed by GOLD 5.1.

\section{Results}

\subsection{Network Analysis Results of Meridian Return of Maxing Shigan Decoction}

Maxing Shigan Decoction in the meridian network of Chinese medicine, the most connected is the lung, the degree value is 4 , followed by the stomach, the degree value is 2 . Among them, the green node represents Chinese medicine, and the red node represents meridian tropism (Figure 1).

\subsection{Target Results of Maxing Shigan Decoction}

Through TCMSP database, BATMAN-TCM database and literature research, we got 327 compounds and 2722 targets of Maxing Shigan Decoction (Table 1).

Among them, there are 7 cytokines related to COVID-19, including Interleukin $1 \beta$ (IL-1 13$)$, tumor necrosis factor a (TNF-a), Interleukin 10 (IL-10), CRP, IL-6, Interleukin 2 (IL-2) and CXC Chemokine Ligand 10 (CXCL10) (Table 2).

\subsection{Visualization Results of the Common Target of Maxing Shigan Decoction}

By using omicshare online mapping software to integrate and analyze the common target of "Maxing Shigan Decoction-acute lung injury and myocardial injury" and make Venn map, 189 common targets are obtained (Figure 2). Among them, $98.5 \%$ of the acute lung injury targets are the same as that of Maxing Shigan Decoction, and $5.8 \%$ of the myocardial injury targets are the same as that of Maxing Shigan Decoction.

\subsection{Screening Results of Key Targets}

Through screening the degree value of target interaction, 30 key targets are obtained (Figure 3). These targets are Insulin (INS), AKT Serine/threonine Kinase 1 (AKT1), IL-6, Albumin (ALB), Vascular Endothelial Growth Factor A (VEGFA), Tumor Necrosis Factor (TNF), Mitogen-Activated Protein Kinase 3 (MAPK3), Tumor Protein P53 (TP53), C-C Motif Chemokine Ligand 2 (CCL2), Mitogen-Activated Protein Kinase 1(MAPK1), IL-10, IL-1 $\beta$, Prostaglandin-Endoperoxide Synthase 2 (PTGS2), Matrix Metallopeptidase 9 
(MMP9), Epidermal Growth Factor Receptor (EGFR), Mitogen-Activated Protein Kinase 8 (MAPK8), Toll Like Receptor 4 (TLR4), Nitric Oxide Synthase 3 (NOS3), Signal Transducer and Activator Of Transcription 3 (STAT3), Intercellular Adhesion Molecule 1 (ICAM1), Peroxisome Proliferator Activated Receptor Gamma (PPARG), Vascular Cell Adhesion Molecule 1 (VCAM1), Insulin Like Growth Factor 1 (IGF1), CRP, Amyloid Beta Precursor Protein (APP), Matrix Metallopeptidase 2 (MMP2), Fibroblast Growth Factor 2 (FGF2), C-X-C Motif Chemokine Receptor 4 (CXCR4), Leptin (LEP), Endothelin 1 (EDN1). These 30 targets may be the key role of Maxing Shigan Decoction in the intervention of COVID-19.

\subsection{Gene Enrichment Analysis Results}

Using the $G O$ analysis $(P<0.05)$ in Omicshare, the 189 common targets obtained from the intersection of "1.3" including 2047 items of Biological Process, 28 items of Cell Composition and 50 items of Molecular Function. Among them, Biological Process was mainly related to the regulation of active oxygen metabolism process, oxidative stress response, active oxygen metabolism process, muscle cell proliferation, etc. Cell Composition is mainly related to membrane area, platelet alpha granule cavity, RNA polymerase II transcription factor complex etc. Molecular Function is mainly related to receptor ligand activity, cytokine activity, cytokine receptor binding, viral receptor activity, MAP kinase activity, protease binding, etc. (Figure 4).

According to KEGG analysis $(\mathrm{P}<0.05), 149$ pathways were enriched, mainly related to Hypoxia inducible Factor 1(HIF-1) signaling pathway, tumor necrosis factor signaling pathway, Interleukin 17 (IL-17) signaling pathway, Mitogen-Activated Protein Kinase (MAPK) signaling pathway, C-type lectin receptor signaling pathway, etc. The top 20 were selected according to $p$ value for visualization (Figure 5).The bubble size indicates the number of genes enriched in the entry. The larger the bubble, the more genes enriched in the entry. The bubble color indicates the $p$ value. The redder the bubble, the smaller the $p$ value of the entry.

\subsection{Molecular docking results}

The top 15 compounds with ACE2, IL-6 and GM-CSF docking scores were counted (Table 3). The highest scores for docking with the A site of ACE2 are: Supraene, Gancaonin H and $(6 \mathrm{Z}, 10 \mathrm{E}, 14 \mathrm{E}, 18 \mathrm{E})-2,6,10$, $15,19,23$-hexamethyltetracosa-2, 6, 10, 14, 18, 22-hexaene. The highest scores for docking with the $B$ site of ACE2 are: Licorice Glycoside E, Supraene and (6Z, 10E, 14E, 18E)-2, 6, 10, 15, 19, 23-

hexamethyltetracosa-2, 6, 10, 14, 18, 22-hexaene. The highest scores for docking with IL-6 are: Supraene, Glycyrin and (6Z, 10E, 14E, 18E)-2, 6, 10, 15, 19, 23-hexamethyltetracosa-2, 6, 10, 14, 18 22-hexaene. The highest scores for docking with GM-CSF are Licorice Glycoside E, Supraene, $(6 Z, 10 \mathrm{E}, 14 \mathrm{E}, 18 \mathrm{E})-2,6,10$, $15,19,23$-hexamethyltetracosa-2, 6, 10, 14, 18, 22-hexaene. It is suggested that these ingredients may play a role in the intervention of COVID-19 by Maxing Shigan Decoction. 
It can be seen that the A site of the target protein ACE2 binds to the active components of Ephedra, Licorice and Almond (Figure 6A), these three components belong to the long chain type. When combined with ACE2, one end of the long chain enters the inside and the other end is exposed to the outside. Most of the ligands in the spiral gap of ACE2 overlap, and the exposed parts have different shapes. Figure $6 \mathrm{~B} \sim \mathrm{D}$ show the combination mode of the active ingredients of Licorice, Ephedra and AlmondLicorice and Almond with ACE2, they are somewhat similar to the conformation when ACE2 is bound. It is possible that molecules of this structure can better bind to the ACE2 target protein. These three components have very high docking scores with ACE2. It is predicted that these three components of Ephedra, Licorice and Almond may prevent the new coronavirus from entering human cells by acting on the target ACE2.

The combination model of the three active ingredients with the highest results of Licorice, Ephedra and Almond docking with ACE2 B site and ACE2 B site (Figure 7). It can be found (Figure 7A) that the position of the B site of the target protein ACE2 is located, and the key amino acids at this site are His345, Pro346, Glu375, and Tyr515, respectively. Although the score of the active ingredient binding to the $B$ site is also very high, compared with the A binding site, the B site of ACE2 is slightly farther from the S protein binding site of the new coronavirus, which may not Direct effect, but whether the catalytic activity of the $B$ site is enhanced or inhibited, and whether it plays a key role in the inflammatory storm caused by the virus requires further experimental verification.

It shows the docking model of IL-6 with the active ingredients of Ephedra, Licorice and Almond (Figure 8). It can clearly see the active position of the active component when it is docked with IL-6 (Figure 8A). The conformation of the three active ingredients of Ephedra, Licorice and Almond showed only a small overlap, which was roughly "V" shape. It may be that this conformation could make the molecule better bind to IL-6 target protein. The docking model of glycyrin and IL-6 are a typical "V" type (Figure 8B). This is due to the interaction of various forces (such as hydrogen bond, hydrophobic) formed by glycorin and key amino acids in the active site. It shows the binding mode of the active ingredients of Ephedra and Almond and IL-6, respectively (Figure 8C D). These three docking models have the highest scores of all active ingredients in Ephedra, Licorice and Almond. It is predicted that these three ingredients can be combined with IL-6 to achieve the effect of suppressing inflammatory storms.

Figure 9A shows the crystal structure of GM-CSF. The parts marked in the figure are the active sites where the active ingredients of Ephedra, Licorice and Almond bind to the target protein. From the enlarged view, the structure of these three active ingredients are all long-chain, and a large part of the conformation coincides. Especially the docking models of (6Z, 10E, 14E, 18E)-2, 6, 10, 15, 19, 23-hexamethyletracosa-2, $6,10,14,18,22$-hexaene and GM-CSF in Ephedra and Almond almost coincide. This is related to the similarity of GM-CSF to the structure of the active ingredient and the action of key amino acids in the active cavity. From Figure 9B D, the docking model of Glycyrin and GM-CSF in Licorice is different from the other (Figure 9B). It may be because the different parts have two ring structures, which just form a strong force with certain amino acids in the pocket, making its conformation present a "U" shape. The conformations of the other two active components show a "one" shape. The three active ingredients of Ephedra, Licorice and Almond are all in the cavity of GM-CSF, and the combined scores are very high. It is 
predicted that Ephedra, Licorice and Almond will act on the target GM-CSF through these three effective components, and then achieve the effect of inhibiting inflammatory storm.

\section{Discussion}

Maxing Shigan Decoction has the functions of anti-influenza virus, anti-inflammatory, antitussive, regulating immune function and improving blood circulation [12]. As a recommended prescription in the process of fighting the epidemic, it is mainly used in the treatment of ordinary and critically ill patients [10]. It shows that Maxing Shigan Decoction may intervene in COVID-19 through anti-inflammatory, antiviral, immune regulation and other aspects.

According to the epidemiological survey, the virus is of the same family as the "SARS" virus and has a strong infectivity to humans. The lung is the main injury site, and is accompanied by different degrees of myocardial damage [7,13-15]. After SARS-CoV-2 infection, Cluster of Differentiation $4^{+} \mathrm{T}$ cells are activated to produce GM-CSF and IL-6, GM-CSF continues to activate Cluster of Differentiation $14^{+}$, Cluster of Differentiation $16^{+}$inflammatory monocytes, promoting specific inflammatory cytokines (TNFa, IL-1 $\beta$, IL-6, IL-10) and excessive release of chemokines eventually lead to immune overexpression and inflammatory cytokine storm, prompting a large number of cell deaths, triggering lung and heart injury.

According to relevant studies, the application of Maxing Shigan Decoction in patients with subacute infective endocarditis can protect heart function, inhibit inflammatory response, and reduce clinical symptoms [16]. Maxing Shigan Decoction can significantly improve lung function in pulmonary fibrosis rat model and clinical treatment alone or in combination with western medicine [17]. Peng Xiufeng et al. [18] found that Maxing Shigan Decoction has a good effect on preventing and treating acute lung injury, and it has a significant regulating effect on the changes of cytokines TNF- $a$ and IL-10 levels in rat serum. The mechanism may be related to Regulation of abnormal changes in TNF- $a$ and IL-10 levels. Maxing Shigan Decoction improves the acute lung injury induced by $\mathrm{H} 1 \mathrm{~N} 1$ by reducing the apoptosis of lung cells and the content of TNF- $a$ in serum [19]. Maxing Shigan Decoction can reduce the expression and release of TNF- $a$, IL- $1 \beta$ and IL- 6 in alveolar lavage fluid, improve lung inflammation, and resist acute lung injury caused by influenza virus infection [20]. Maxing Shigan Decoction can down-regulate the secretion level and protein expression level of Interferon a (IFN- $a$ ) and Interferon $\beta$ (IFN- $\beta$ ) of macrophage infected with influenza virus [21]. Maxing Shigan Decoction can also improve the body's immune function and regulate the expression and secretion of cytokines, thereby reducing lung inflammation and improving the general condition of influenza virus pneumonia mice [22].

Through network pharmacology analysis, the key targets of Maxing Shigan decoction are Insulin (INS), AKT Serine/threonine Kinase 1 (AKT1), IL-6, Albumin (ALB), Vascular Endothelial Growth Factor A (VEGFA), Tumor Necrosis Factor (TNF), Mitogen-Activated Protein Kinase 3 (MAPK3), Tumor Protein P53 (TP53), C-C Motif Chemokine Ligand 2 (CCL2), Mitogen-Activated Protein Kinase 1(MAPK1), IL-10, IL-1 $\beta$, Prostaglandin-Endoperoxide Synthase 2 (PTGS2), Matrix Metallopeptidase 9 (MMP9), Epidermal Growth Factor Receptor (EGFR), Mitogen-Activated Protein Kinase 8 (MAPK8), Toll Like Receptor 4 (TLR4), Nitric 
Oxide Synthase 3 (NOS3), STAT3, Intercellular Adhesion Molecule 1 (ICAM1), Peroxisome Proliferator Activated Receptor Gamma (PPARG), Vascular Cell Adhesion Molecule 1 (VCAM1), Insulin Like Growth Factor 1 (IGF1), CRP, Amyloid Beta Precursor Protein (APP), Matrix Metallopeptidase 2 (MMP2), Fibroblast Growth Factor 2 (FGF2), C-X-C Motif Chemokine Receptor 4 (CXCR4), Leptin (LEP), Endothelin 1 (EDN1). Among them, IL- 6 is an important cytokine expressed by the immune system in the initial response to injury and infection. It can activate JAK/STAT signal pathway in the early stage, regulate $B$ cell differentiation, plasma cell generation and a series of acute phase reactions. IL-6 plays a key role in the acute inflammatory response [23], mainly accelerating the alveolar inflammatory response in the early stage of pulmonary fibrosis through chemotactic inflammatory cell aggregation and promoting inflammatory cell infiltration And then it can mediate the occurrence of idiopathic pulmonary fibrosis and damage the lung [24], which can be used as the initial diagnosis of infectious diseases. MitogenActivated Protein Kinase (MAPK) family members MAPK1, MAPK3, MAPK8 are activated under oxidative stress, viral infection, cancer, etc. [25], respond to cellular inflammatory response and tumor cell proliferation, differentiation, transformation and apoptosis the regulation of death has a significant impact [26]. As an early inflammatory response factor, TNF can activate neutrophils, macrophages, monocytes, etc., release oxygen free radicals, protease, etc., and cause the cascade amplification of inflammatory response [27]. Vascular Endothelial Growth Factor A (VEGFA) is a highly specific vascular endothelial growth factor, which can promote vascular permeability, extracellular matrix degeneration, endothelial cell migration, proliferation and angiogenesis. It was found that serum Vascular Endothelial Growth Factor (VEGF) level in patients with severe pneumonia was closely related to myocardial damage [28]. Matrix Metalloprotein (MMP) can be involved in vascular remodeling, atherosclerosis and collagen degradation of myocardial matrix, which can lead to arrhythmia and even heart failure [29]. STAT3 is one of the main members of the Stat family. STAT3 can regulate the biological behavior of tumor cells and immune cells by mediating the signal of extracellular inflammatory factors. It is an indispensable key molecule in the process of chronic inflammation promoting tumorigenesis and tumor related inflammation [30].

The results of go enrichment showed that in biological processes, the main enrichment items are the regulation of active oxygen metabolism, oxidative stress, active oxygen metabolism, and muscle cell proliferation. In molecular functions, the main enrichment items are receptor ligand activity, cytokine activity, cytokine receptor binding, viral receptor activity, MAP kinase activity, protease binding, etc. Current research shows that the infection of the new coronavirus will cause severe immune and inflammatory reactions, so the signal pathways closely related to the virus, inflammation and immunity may interfere with the new coronavirus. KEGG analysis enriched a total of 149 pathways, mainly related to HIF-1 signaling pathway, tumor necrosis factor signaling pathway, Interleukin 17 (IL-17) signaling pathway, MAPK signaling pathway, and C-type lectin receptor signaling pathway. HIF-1 a expression can be detected in inflammatory diseases such as immune inflammation, bacterial infection, macrophage metabolism, and viral infection [31], Nuclear Factor Kappa Beta (NF-K $\beta$ ) is a key immunoregulatory factor, which can enhance the role of HIF-1a in inflammation by regulating the downstream HIF 1a [32]. Toll like Receptors (TLRs) are a kind of important pattern recognition receptors, which play an important role in 
anti infective immune and inflammatory response. Toll like Receptor 7 (TLR-7) signaling pathway can activate the downstream Nuclear Factor Kappa Beta (NF-k $\beta$ ) signaling pathway through the transmission of cascade reaction signals, further leading to the increase of downstream IL- 6 and TNF-a level, thus initiating the innate immune and adaptive immune process of the body for pathogenic microorganisms [33]. IL-23/IL-17 signaling pathway is the key pathway for the activation and maintenance of $T$ helper cell 17 (Th17), which can play an important role in a variety of inflammatory diseases, such as inflammatory bowel disease, rheumatoid arthritis, multiple sclerosis and other diseases [34]. It suggests that novel coronavirus pneumonia may improve the lung injury induced by inflammation caused by new crown pneumonia.

Through molecular docking, it was found that supraene, the active compound in Ephedra, showed strong binding ability to both sites of ACE2, The active compounds (6Z, 10E, 14E, 18E) - 2, 6, 10, 15, 19, 23hexamethyletracosa-2, 6, 10, 14, 18, 22-hexaene in Almond also showed high binding capacity to the two sites of ACE2, Gancanin H, the active substance of Licorice uralensis Fisch, has a strong binding ability to a site of ACE2, while Licorice Glycoside $E$ has a strong binding ability to B site of ACE2. At the same time, supraene, an active compound in Ephedra, and (6Z, 10E, 14E, 18E) - 2, 6, 10, 15, 19, 23-

hexamethyletracosa-2, 6, 10, 14, 18, 22-hexaene, an active compound in Licorice, have strong binding ability to GM-CSF and IL-6. It has been found that squalene has a strong biological activity, which can reduce blood pressure, lipid and viscosity after ingestion. It can quickly promote blood vessel dredging, prevent and treat heart disease and hypertension caused by poor blood circulation. It also has the oxygen uptake function similar to red blood cells, providing sufficient oxygen for tissue cells in the body, so as to improve cardiovascular and cerebrovascular functions [35]. An analysis of sudden death patients shows that [36], the content of squalene in the heart is very high, a large number of squalene and fatty acids in the phospholipid bilayer of cell membrane form a complex, stabilize the structure of cell membrane, and play a protective role in myocardial damage caused by oxidative damage. Farvin et al. [37] investigated the preventive effect of squalene on myocardial infarction induced by isoproterenol in male rats. The results showed that squalene could significantly prevent the adverse changes of isoproterenol induced protein and glycoprotein levels in plasma and heart tissue of rats, and play a protective role on the heart through antioxidant effect. Zhu Yousheng et al. [38] discussed the therapeutic effect of glycyrrhizin on atherosclerosis in rats and its anti-inflammatory and antioxidant activities. The results showed that glycyrrhizin can significantly reduce the content of cholesterol in aorta and regulate the metabolism of blood lipid in atherosclerotic rats, further study found that glycyrrhizin can also reduce the levels of TNF-a and IL1 in the serum of atherosclerotic rats. Therefore, glycyrrhizin has therapeutic effect on atherosclerotic rats.

\section{Conclusion}

In summary, based on network pharmacology and molecular docking analysis, it is believed that Maxing Shigan Decoction may pass through the active compounds of Ephedra and Almond Supraene, $(6 \mathrm{Z}, 10 \mathrm{E}$, $14 \mathrm{E}, 18 \mathrm{E})-2,6,10,15,19,23$-hexamethyltetracosa-2, 6, 10, 14, 18, 22-hexaene acts on three targets of ACE2, GM-CSF and IL-6, and the active compound Glycyrin of Licorice acts on two targets of GM-CSF and 
IL-6, Gancaonin H and Licorice Glycoside E act on the A and B sites of ACE2, respectively, and coordinate multiple pathways to exert anti-inflammatory and antiviral effects to prevent and treat pulmonary heart damage caused by SARS-COV-2.

\section{Declarations}

\section{Conflict of Interests}

The authors declare that the research was conducted in the absence of any commercial or financial relationships that could be construed as a potential conflict of interest.

\section{Author Contributions}

Professor DL and professor YQ and professor XJ organized thoughts for the article and revised the manuscript. JS and WQ were responsible for the writing of the article and the inquiry of the information. WY and YJ offered opinions for the drawing of diagrams and charts in the article. All authors read and approved the final version of the manuscript.

\section{Funding}

This project was supported by the National Natural Science Foundation of China (grant numbers 81760789), Special project on emergency prevention and treatment of COVID-19 in Gansu University of Chinese Medicine (2020XNYJ-05); Provincial key talent project (GZT2020-9-1).

\section{Acknowledgments}

We acknowledge Gansu University of Chinese Medicine, Provincial-level Key Laboratory for Molecular Medicine ofMajor Diseases and The Prevention and Treatment with Traditional Chinese Medicine Research in Gansu Colleges and University for providing support and assistance for this article.

\section{References}

[1] National Health Comission of the People's Republic of China. Notice on novel coronavirus pneumonia diagnosis and treatment plan (trial version 7). (2020). http://www.nhc.gov.cn/yzygj/s7653p/202003/46c9294a7dfe-4cef80dc7f5912eb1989.shtml [Accessed March 9, 2020].

[2] Hu Q. J., Guan, H. X., Sun, Z. Y., Huang, L., Chen, C., Ai, T., et al. (2020). Early CT features and temporal lung changes in COVID-19 pneumonia in Wuhan, China. Eur J Radiol, 128(undefined), 109017. doi:10.1016/j.ejrad.2020.109017 
[3] Liu, X. J., Qu, J. J., Yang, X., and XUE, Y.W. (2020). The characteristics of CT imaging of novel coronavirus pneumonia. Journal of Heze Medical College, 32(01):12-16. doi: 10.3969/j.issn.10084118.2020.01.004

[4] Shi, S. B., Qin, M., Shen, B., Cai, Y. L., Liu, T., Yang, F., et al. (2020). Association of Cardiac Injury with Mortality in Hospitalized Patients With COVID-19 in Wuhan, China. JAMA Cardiol, undefined (undefined), undefined. doi: 10.1001/jamacardio.2020.0950

[5] Wei, J. F., Huang, F. Y., Xiong, T. Y., Liu, Q., Chen, H., Wang, H., et al. (2020). Acute myocardial injury is common in patients with covid-19 and impairs their prognosis. Heart, undefined (undefined), undefined. doi: 10.1136/heartjnl-2020-317007

[6] Dong, N. G., Cai, J., Zhou, Y., Liu, J. W., and Li, F. (2020). End-Stage Heart Failure With COVID-19: Strong Evidence of Myocardial Injury by 2019-nCoV. JACC Heart Fail, 8(6), 515-517. doi:

10.1016/j.jchf.2020.04.001

[7] Xu, X. T., Chen, P., Wang, J. F., Feng, J. N., Zhou, H., Li. X., et al. (2020). Evolution of the novel coronavirus from the ongoing Wuhan outbreak and modeling of its spike protein for risk of human transmission. Sci China Life Sci, 63(3), 457-460. doi: 10.1007/s11427-020-1637-5

[8] Zhang, X. Q., Li, S. R., Niu, and S. Q. (2020). ACE2 and novel coronavirus pneumonia. International Journal of Cardiovascular Disease, 47(02):68-70. doi: 10.3969/j.issn.1673-6583.2020.02.002

[9] He, Y. J., Song, B. Q., Yang, L. Y., Zhang, Y. L., and Liu, W. A. (2020). Discussion on Scientific Basis of Acupuncture Prevention and Treatment of Novel Coronavirus Pneumonia from "Inflammatory Storm" Theory. Modernization of Traditional Chinese Medicine and Materia Medica-World Science and Technology: 1-4. doi: 10.11842/wst.20200228002

[10] Gong, X.Y., Wei, D. R., Gong, X., Xiong, Y., Wang, T., and Mou, F. Z. (2020). Analysis on TCM Clinical Characteristics and Syndromes of 80 Patients with Novel Coronavirus Pneumonia. Chinese Journal of Information on Traditional Chinese Medicine: 1-6. doi: 10.3969/j.issn.1005-5304.202002560

[11] Qu, Y. F., Fang, W., Jin Y. Z., Qin, C., Niu, X.C., Zhang, N., et al. (2020). Forty Cases of Common CoVID19 Treated with Modified Ephedra and Apricot Kernel and Gypsum and Licorice Decoction Combined with Western Medicine Routine Treatment. Henan Traditional Chinese Medicine, (05):666-669. doi: 10.16367/j.issn.1003-5028.2020.05.0167.

[12] Huang, X. J., Wei, G., Zhang, L., and Huang, K. W. (2014). Progress of pharmacological action and clinical application of Maxing Shigan tang. Journal of Guangdong Pharmaceutical University, 30(1):110114. doi: 10.3969/j.issn.1006-8783.2014.01.025

[13] Jin, Y. H., Cai, L., Cheng, Z. S., Cheng, H., Deng, T., Fan, Y. P., et al. (2020). A rapid advice guideline for the diagnosis and treatment of 2019 novel coronavirus (2019-nCoV) infected pneumonia (standard 
version). Medical Journal of Chinese People's Liberation Army, 45(01): 1-20. doi: 10.11855/j.issn.05777402.2020.01.01

[14] National Health Comission of the People's Republic of China. Notice on novel coronavirus pneumonia diagnosis and treatment plan (trial version 5). (2020).

http://www.nhc.gov.cn/xcs/fkdt/202002/e84bd30142ab4d8982326326e4db22ea.shtml. [Accessed February 5, 2020].

[15] Shi, H, S., Han, X. Y., Fan, Y. Q., Liang, B., Yang, F., Han, P., et al. (2020). Radiologic Features of Patients with 2019-nCoV Infection. Journal of Clinical Radiology, 39(01):8-11. doi:

10.13437/j.cnki.jcr.20200206.002.

[16] Deng, W. H. (2013). Clinical application of Maxing Shigan Decoction. Chinese Journal of Clinical Rational Drug Use, 6(16): 180-181. doi囚 10.15887/j.cnki.13-1389/r.2013.16.022

[17] Lin, Z. C., Wu, X. P., and Lin, S. Y. (2018). The effect of Jiawei Maxing Shigan Decoction on the regulation of transforming growth factor $\beta / S$ mad signal pathway in radiation-induced pulmonary fibrosis. Chinese Journal of Critical Care Medicine(Electronic Edition), 11(06): 403-406. doi: 10.3877/cma.j.issn.1674-6880.2018.06.009

[18] Peng, X. F., Shi, X. G., Xu, Y. Y., Huang, Z. J.,and Wang, W. G. (2008). Effect of Maxing Ganshi Decoction on cytokines related to acute lung injury in rats. Journal of Chinese Medicinal Materials, (05): 739-740. doi区 10.13863/j.issn1001-4454.2008.05.042

[19] Zhong, Y., Zhou, J., Liang, N., Liu, B., Lu, R., He, Y., et al. (2016). Effect of Maxing Shigan Tang on H1N1 Influenza A Virus-Associated Acute Lung Injury in Mice. Intervirology, 59(5-6), 267-274. doi: $10.1159 / 000458726$

[20] Li, L., Wei, K., Lu, F. G., Cai, L., Zhang, B., Zhang, S. Y. et al. (2017). Effect of Maxing Shigan Decoction against type $A$ influenza virus infection in mice induced by viral lung injury based on TLR4-MyD88-TRAF6 signal pathways. Chinese Traditional and Herbal Drugs, 48(08): 1591-1596. doi: 10.7501/j.issn.02532670.2017.08.017

[21] Zhang, S. Y., He, G. L., Lu, F.G., Li, L., Zhang, B., Dai, B., et al. (2019). Mechanism research of anti influenza virus of ephedra decocted earlier Maxing Shigan Decoction from the expression level of IFN- $\alpha / \beta$ protein mediated by TLR7/8. China Journal of Traditional Chinese Medicine and Pharmacy, 34 (3): 11881193.

[22] Li, L., Wu J. M., Ouyang, J. J., Hu, J., Liao, C., Yuan, P., et al. (2018). Study on screening and mechanism of effective Chinese medicine for influenza virus pneumonia. Chinese Journal of Immunology, 34 (8): 1168-1173. doi: 10.3969/j.issn.1000-484X.2018.08.009 
[23] Kaur, S., Bansal, Y., Kumar, R., and Bansal, G. (2020). A panoramic review of IL-6: Structure, pathophysiological roles and inhibitors. Bioorg. Med. Chem., 28(5), 115327. doi:

10.1016/j.bmc.2020.115327

[24] Chen, X. H., He, Y. C., Zhou, Y. P.,Chun, Y. T., Huang, Y. S., Yao, C. N., et al. (2001). The relationship between TGF- $\beta$ 1, TNF- $\alpha$ and IL-6 with liver fibrosis. Shanghai J.of Immunology, 21(6): 364-365. doi: 10.3969/j.issn.1001-2478.2001.06.016.

[25] Panteva, M., Korkaya, H., and Jameel, S. (2003). Hepatitis viruses and the MAPK pathway: is this a survival strategy? Virus Research, 92(2), 131-140. doi: 10.1016/s0168-1702(02)00356-8

[26] Zhao, Y., Yang, J. H., Han, J. P., Li, S., Yu, Y. Y., Fan, Z. Z., et al. (2017). Research Progress of MEK/ERK Pathway in Bronchial Asthma Pathogenesis. Chinese Archives of Traditional Chinese Medicine, 35(2): 329-331. doi: 10.13193/j.issn.1673-7717.2017.02.020

[27] Li, T., and Zhang, X. J. (2019). Changes and significance of peripheral blood tumor necrosis factor-a, interleukin-10, platelet parameters and erythrocyte sedimentation rate in patients with sepsis and lung injury. Experimental and Laboratory Medicine, 37(06): 1083-1086. doi: 10.3969/j.issn.16741129.2019 .06 .030

[28] Tao, P., Xia, W. M., and Ai, T. (2019).Changes of serum VEGF, ET-1 and CK-MB in children with severe pneumonia and their relationship with myocardial damage. Journal of Clinical Pulmonary Medicine, 24(8): 1441-1445. doi: 10.3969/j.issn.1009-6663.2019.08.021

[29] Kurzepa, J., Kurzepa, J., Golab, P., Czerska, S., and Bielewicz, J. (2014). The significance of matrix metalloproteinase (MMP)-2 and MMP-9 in the ischemic stroke. International Journal of Neuroscience, 124(10), 707-716. doi: 10.3109/00207454.2013.872102

[30] Yu, H., Pardoll, D., and Jove, R. (2009). STATs in cancer inflammation and immunity: a leading role for STAT3. Nature Reviews Cancer, 9(11), 798-809. doi: 10.1038/nrc2734

[31] Yang, M. S., Zhou, N. Wang, Z. G., and Hao, H. F. (2016). Research Progress on the Role of Transcription Factor HIF-1a and Its Signal Pathway in the Pathogenesis. Biotechnology Bulletin, 32(08): 8-13. doi囚 10.13560/j.cnki.biotech.bull.1985.2016.08.002

[32] Cai, X., Huang, Y., Zhang, X., Wang, S., Zou, Z., Wang, G., et al. (2014). Cloning, characterization, hypoxia and heat shock response of hypoxia inducible factor-1 (HIF-1) from the small abalone Haliotis diversicolor. Gene, 534(2), 256-264. doi: 10.1016/j.gene.2013.10.048

[33] Pan, Y. D., Pan, X. D., Li, J., Chen, R., and Han, Z. (2020). Detection of inflammatory factors secondary to pulmonary infection and analysis of the role of TLR7/IL-23/IL-17 signaling pathway in chronic obstructive pulmonary disease. Chinese Journal of Nosocomiology, (07): 994-998. doi:

10.11816/cn.ni.2020-191144 
[34] Zeng, L. X., Xiao, C. W., Sun, J. Y., Wang, J.J., and Yang, L. (2020).Changes of expression of inflammatory factors and activity of IL-23/IL-17 signaling pathway in patients with chronic hepatitis B. Chinese Journal of Nosocomiology, (10):1512-1516. doi: 10.11816/cn.ni.2020-191552

[35] Qiu, C. M. and Yin, G. L. (2013). Study on the Effects of Squalene Softgel on Enhancing Anoxia Endurance Function. Journal of the Chinese Cereals and Oils Association, 28(02): 52-54. doi:10.3969/j.issn.1003-0174.2013.02.011

[36] Narayan Bhilwade, H., Tatewaki, N., Nishida, H., and Konishi, T. (2010). Squalene as Novel Food Factor. Current Pharmaceutical Biotechnology, 11(8), 875-880. doi: 10.2174/138920110793262088

[37] Farvin, K. H. S., Kumar, S. H. S., Anandan, R., Mathew, S., Sankar, T. V., and Nair, P. G. V. (2007). Supplementation of squalene attenuates experimentally induced myocardial infarction in rats. Food Chemistry, 105(4), 1390-1395. doi: 10.1016/j.foodchem.2007.05.034

[38] Zhu, Y. S., and Chu, J. (2015). Effect and mechanism of glycyrrhizin on atherosclerosis in rats. Guangdong Medical Journal, 36 (3):365-368. doi: 10.13820/j.cnki.gdyx.2015.03.012

\section{Tables}

Table.1 The number of active compounds and targets of each medicine in Maxing Shigan Decoction

\begin{tabular}{|lll|}
\hline Names of Chinese Medicine in the Database & Number of Compounds & TargetPoints \\
\hline Ephedra & 125 & 1391 \\
\hline Licorice & 156 & 832 \\
\hline Almond & 43 & 496 \\
\hline Gypsum & 3 & 3 \\
\hline
\end{tabular}

Table.2 Frequency of action of inflammatory factors 


\begin{tabular}{|c|c|c|c|}
\hline $\begin{array}{l}\text { Inflammatory } \\
\text { Factors }\end{array}$ & Frequency & $\begin{array}{l}\text { TraditionalChinese } \\
\text { Medicine }\end{array}$ & Chemical Compound \\
\hline \multirow[t]{3}{*}{ IL-6 } & 15 & Licorice & Quercetin, Urea,Tetrahydropalmatine \\
\hline & & Ephedra & $\begin{array}{l}\text { Quercetin, Luteolin, Pseudoephedrine, Ethanol, } \\
\text { Carvacrol, Thymol, D-Pseudoephedrine, } \\
\text { Ephedrine, 1-Octanol, Hexanol, N-Triacontanol }\end{array}$ \\
\hline & & Gypsum & Interleukin-6 \\
\hline \multirow[t]{3}{*}{ IL-10 } & 23 & Licorice & $\begin{array}{l}\text { 3-Methyl-6,7,8-Trihydropyrrolo[1,2-A]Pyrimidin-2- } \\
\text { One }\end{array}$ \\
\hline & & Ephedra & $\begin{array}{l}\text { Pseudoephedrine, DecanoicAcid, } \\
\text { DodecanoicAcid, HeptanoicAcid, } \\
\text { HexadecanoicAcid, LauricAcid, NonanoicAcid, } \\
\text { OctadecanoicAcid, PentadecanoicAcid, } \\
\text { TetradecanoicAcid, Piperitone, Carvacrol, } \\
\text { Thymol, 6-Methyl-5-Hepten-2-One, Alpha-lonone, } \\
\text { Beta-lonone, Dihydro-Beta-lonone, Styrene, D- } \\
\text { Pseudoephedrine, Ephedrine }\end{array}$ \\
\hline & & Almond & TerpinyIAcetate, ArachidicAcid \\
\hline \multirow[t]{4}{*}{ IL-1 $\beta$} & 22 & Licorice & Quercetin, Tetrahydropalmatine \\
\hline & & Ephedra & $\begin{array}{l}\text { Quercetin, D-Norpseudoephedrine, } \\
\text { Pseudoephedrine, Carvacrol, Thymol, Alpha- } \\
\text { Pinene, Alpha-Terpinolene, Beta-Pinene, Gamma- } \\
\text { Terpinene, Limonene, Myrcene, Sabinene, D- } \\
\text { Pseudoephedrine, Ephedrine, Alpha- } \\
\text { LinolenicAcid, LinoleicAcid, LinolenicAcid }\end{array}$ \\
\hline & & Almond & Terpinolene, 1-Nonene \\
\hline & & Gypsum & Interleukin-1beta \\
\hline \multirow[t]{3}{*}{ CRP } & 21 & Licorice & $\begin{array}{l}\text { Quercetin, 3-Methyl-6,7,8-Trihydropyrrolo[1,2- } \\
\text { A]Pyrimidin-2-One }\end{array}$ \\
\hline & & Ephedra & $\begin{array}{l}\text { Quercetin, 2,4-Decadienal, 2-Methyl-2-Butenal, } \\
\text { Safranal, Trans-2-Nonenal, Beta-Cyclocitral, } \\
\text { Piperitone, Carvacrol, Thymol, 6-Methyl-5- } \\
\text { Hepten-2-One, Alpha-lonone, Beta-lonone, } \\
\text { Dihydro-Beta-lonone, DibutylPhthalate, } \\
\text { DimethylPhthalate, IsobutylBenzoate, } \\
\text { MethylBenzoate }\end{array}$ \\
\hline & & Almond & |El-2-Nonenal, Citral \\
\hline \multirow[t]{2}{*}{ IL-2 } & 12 & Licorice & Quercetin \\
\hline & & Ephedra & $\begin{array}{l}\text { Quercetin, Luteolin, D-Norpseudoephedrine, } \\
\text { Norephedrine, Norpseudoephedrine, } \\
\text { Pseudoephedrine, 3,4-Dimethyl-5- } \\
\text { Phenyloxazolidine, D-Pseudoephedrine, } \\
\text { Ephedrine, Methylpseudoephedrine, N- } \\
\text { Methylephedrine }\end{array}$ \\
\hline
\end{tabular}




\begin{tabular}{|llll|}
\hline CXCL-10 & 2 & Licorice & Quercetin \\
\hline & & Ephedra & Quercetin \\
\hline TNF-a & 1 & Gypsum & Tumornecrosisfactor \\
\hline
\end{tabular}

Table.3 Docking results of Ephedra, Licorice and Almond active ingredients with ACE2, IL-6 and GM-CSF 


\begin{tabular}{|c|c|c|c|c|}
\hline ID & Compound & $\begin{array}{l}\text { Traditional } \\
\text { Chinese } \\
\text { Medicine }\end{array}$ & Targets & $\begin{array}{l}\text { Goldscore } \\
\text { Fitness }\end{array}$ \\
\hline MOL002372 & $\begin{array}{l}(6 \mathrm{Z}, 10 \mathrm{E}, 14 \mathrm{E}, 18 \mathrm{E})-2,6,10,15,19,23- \\
\text { hexamethyltetracosa-2,6,10,14, 18,22- } \\
\text { hexaene }\end{array}$ & Almond & ACE2-A & 70.28 \\
\hline MOL001506 & Supraene & Ephedra & ACE2-A & 62.58 \\
\hline MOL010922 & Diisooctyl succinate & Almond & ACE2-A & 60.96 \\
\hline MOL002211 & 11,14-eicosadienoic acid & Almond & ACE2-A & 60.9 \\
\hline MOL005001 & Gancaonin $\mathrm{H}$ & Licorice & ACE2-A & 56.15 \\
\hline MOL004355 & Spinasterol & Almond & ACE2-A & 55.8 \\
\hline MOL004917 & Glycyroside & Licorice & ACE2-A & 55.55 \\
\hline MOL004857 & Gancaonin B & Licorice & ACE2-A & 55.46 \\
\hline MOL004866 & $\begin{array}{l}\text { 2-(3,4-dihydroxyphenyl)-5,7-dihydroxy-6-(3- } \\
\text { methylbut-2-enyl)chromone }\end{array}$ & Licorice & ACE2-A & 54.51 \\
\hline MOL004879 & Glycyrin & Licorice & ACE2-A & 53.82 \\
\hline MOL004811 & Glyasperin C & Licorice & ACE2-A & 53.52 \\
\hline MOL000953 & $\mathrm{Clr}$ & Almond & ACE2-A & 52.71 \\
\hline MOL004815 & $\begin{array}{l}\text { (e)-1-(2,4-dihydroxyphenyl)-3-(2,2- } \\
\text { dimethylchromen-6-yl)prop-2-en-1-one }\end{array}$ & Licorice & ACE2-A & 52.64 \\
\hline MOL005017 & Phaseol & Almond & ACE2-A & 52.32 \\
\hline MOL001494 & Mandenol & Ephedra & ACE2-A & 52.27 \\
\hline MOL004860 & Licorice Glycoside E & Licorice & ACE2-B & 72.42 \\
\hline MOL002372 & $\begin{array}{l}(6 \mathrm{Z}, 10 \mathrm{E}, 14 \mathrm{E}, 18 \mathrm{E})-2,6,10,15,19,23- \\
\text { hexamethyltetracosa-2,6,10,14, 18,22- } \\
\text { hexaene }\end{array}$ & Almond & ACE2-B & 67.26 \\
\hline MOL001506 & Supraene & Ephedra & ACE2-B & 65.92 \\
\hline MOL004879 & Glycyrin & Licorice & ACE2-B & 65.25 \\
\hline MOL004917 & Glycyroside & Licorice & ACE2-B & 64.00 \\
\hline MOL004848 & Licochalcone G & Licorice & ACE2-B & 63.50 \\
\hline MOL004989 & 6-prenylated eriodictyol & Licorice & ACE2-B & 63.49 \\
\hline MOL003656 & Lupiwighteone & Licorice & ACE2-B & 63.38 \\
\hline MOL004824 & $\begin{array}{l}\text { (2s)-6-(2,4-dihydroxyphenyl)-2-(2- } \\
\text { hydroxypropan-2-yl)-4-methoxy-2,3- }\end{array}$ & Licorice & ACE2-B & 63.31 \\
\hline
\end{tabular}


dihydrofuro[3,2-g]chromen-7-one

\begin{tabular}{|c|c|c|c|c|}
\hline MOL005020 & Dehydroglyasperins C & Licorice & ACE2-B & 63.24 \\
\hline MOL001494 & Mandenol & Ephedra & ACE2-B & 61.99 \\
\hline MOL004857 & Gancaonin B & Licorice & ACE2-B & 61.81 \\
\hline MOL004882 & Licocoumarone & Licorice & ACE2-B & 60.69 \\
\hline MOL004866 & $\begin{array}{l}\text { 2-(3,4-dihydroxyphenyl)-5,7-dihydroxy-6-(3- } \\
\text { methylbut-2-enyl)chromone }\end{array}$ & Licorice & ACE2-B & 60.48 \\
\hline MOL005012 & Licoagroisoflavone & Licorice & ACE2-B & 60.48 \\
\hline MOL004860 & Licorice Glycoside E & Licorice & $\begin{array}{l}\text { GM- } \\
\text { CSF }\end{array}$ & 79.75 \\
\hline MOL001506 & Supraene & Ephedra & $\begin{array}{l}\text { GM- } \\
\text { CSF }\end{array}$ & 71.16 \\
\hline MOL002372 & $\begin{array}{l}(6 \mathrm{Z}, 10 \mathrm{E}, 14 \mathrm{E}, 18 \mathrm{E})-2,6,10,15,19,23- \\
\text { hexamethyltetracosa-2,6,10,14, 18,22- } \\
\text { hexaene }\end{array}$ & Almond & $\begin{array}{l}\text { GM- } \\
\text { CSF }\end{array}$ & 68.57 \\
\hline MOL002211 & 11,14-eicosadienoic acid & Almond & $\begin{array}{l}\text { GM- } \\
\text { CSF }\end{array}$ & 68.28 \\
\hline MOL011319 & Truflex obp & Ephedra & $\begin{array}{l}\text { GM- } \\
\text { CSF }\end{array}$ & 65.02 \\
\hline MOL004924 & (-)-medicocarpin & Licorice & $\begin{array}{l}\text { GM- } \\
\text { CSF }\end{array}$ & 63.42 \\
\hline MOL010922 & Diisooctyl succinate & Almond & $\begin{array}{l}\text { GM- } \\
\text { CSF }\end{array}$ & 62.96 \\
\hline MOL004811 & Glyasperin C & Licorice & $\begin{array}{l}\text { GM- } \\
\text { CSF }\end{array}$ & 61.75 \\
\hline MOL004917 & Glycyroside & Licorice & $\begin{array}{l}\text { GM- } \\
\text { CSF }\end{array}$ & 61.53 \\
\hline MOL001494 & Mandenol & Ephedra & $\begin{array}{l}\text { GM- } \\
\text { CSF }\end{array}$ & 61.43 \\
\hline MOL004879 & Glycyrin & Licorice & $\begin{array}{l}\text { GM- } \\
\text { CSF }\end{array}$ & 61.17 \\
\hline MOL004806 & Euchrenone & Licorice & $\begin{array}{l}\text { GM- } \\
\text { CSF }\end{array}$ & 60.89 \\
\hline MOL005000 & Gancaonin G & Licorice & $\begin{array}{l}\text { GM- } \\
\text { CSF }\end{array}$ & 60.77 \\
\hline MOL005012 & Licoagroisoflavone & Licorice & $\begin{array}{l}\text { GM- } \\
\text { CSF }\end{array}$ & 60.31 \\
\hline MOL004857 & Gancaonin B & Licorice & GM- & 60.09 \\
\hline
\end{tabular}




\begin{tabular}{|lllll|}
\hline MOL001506 & Supraene & Eshedra & IL-6 & 79.93 \\
\hline MOL002372 & $\begin{array}{l}(6 Z, 10 E, 14 E, 18 E)-2,6,10,15,19,23- \\
\text { hexamethyltetracosa-2,6,10,14,18,22- } \\
\text { hexaene }\end{array}$ & Almond & IL-6 & 73.46 \\
\hline MOL004879 & Glycyrin & Licorice & IL-6 & 70.01 \\
\hline MOL004857 & Gancaonin B & Licorice & IL-6 & 69.67 \\
\hline MOL004903 & Liquiritin & Licorice & IL-6 & 69.55 \\
\hline MOL004903 & Liquiritin & Almond & IL-6 & 69.55 \\
\hline MOL002211 & 11,14-eicosadienoic acid & Almond & IL-6 & 69.48 \\
\hline MOL004882 & Licocoumarone & Licorice & IL-6 & 69.43 \\
\hline MOL004917 & Glycyroside & Licorice & IL-6 & 69.42 \\
\hline MOL004856 & Gancaonin A & Licorice & IL-6 & 69.29 \\
\hline MOL011319 & Truflex obp & Ephedra & IL-6 & 68.02 \\
\hline MOL005020 & Dehydroglyasperins C & Licorice & IL-6 & 67.99 \\
\hline MOL004864 & $\begin{array}{l}\text { 5,7-dihydroxy-3-(4-methoxyphenyl)-8-(3- } \\
\text { methylbut-2-enyl)chromone }\end{array}$ & Licorice & IL-6 & 65.75 \\
\hline MOL004866 & $\begin{array}{l}\text { 2-(3,4-dihydroxyphenyl)-5,7-dihydroxy-6-(3- } \\
\text { methylbut-2-enyl)chromone }\end{array}$ & Licorice & IL-6 & 65.64 \\
\hline MOL002311 & Glycyrol & Licorice & IL-6 & 64.92 \\
\hline
\end{tabular}

\section{Figures}

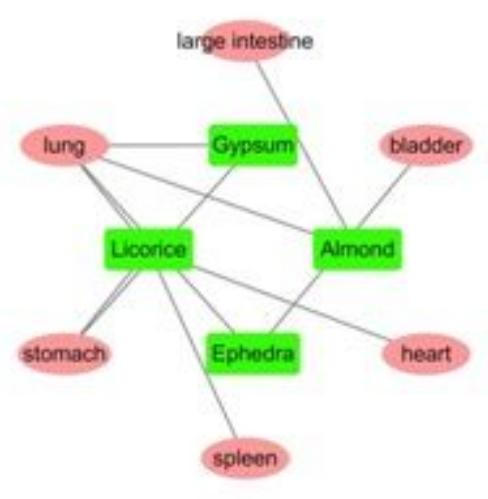

Figure 1

network of medicine meridian tropism of Maxing Shigan Decoction 


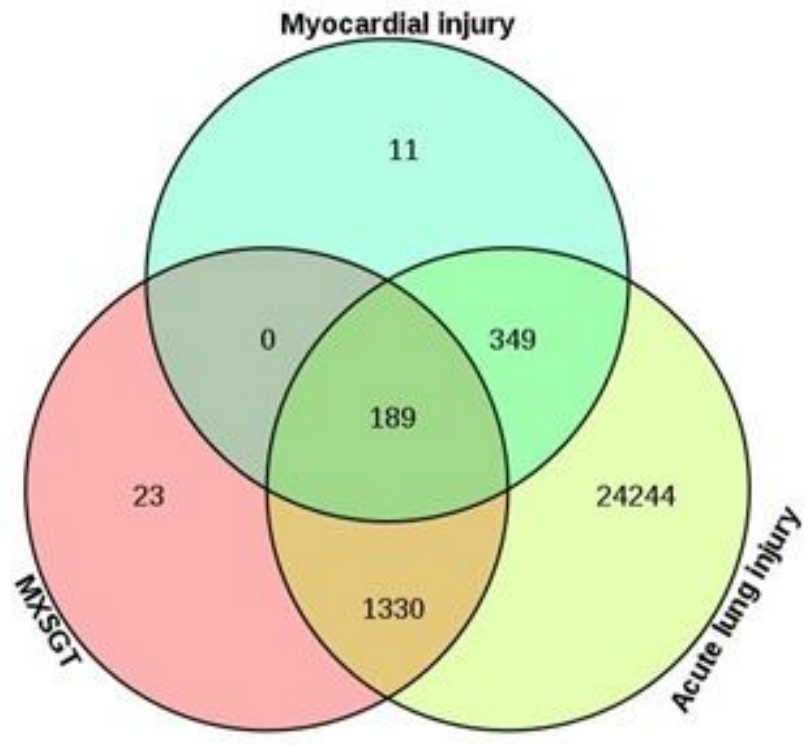

Figure 2

Maxing Shigan Decoction-common target of lung and heart injury

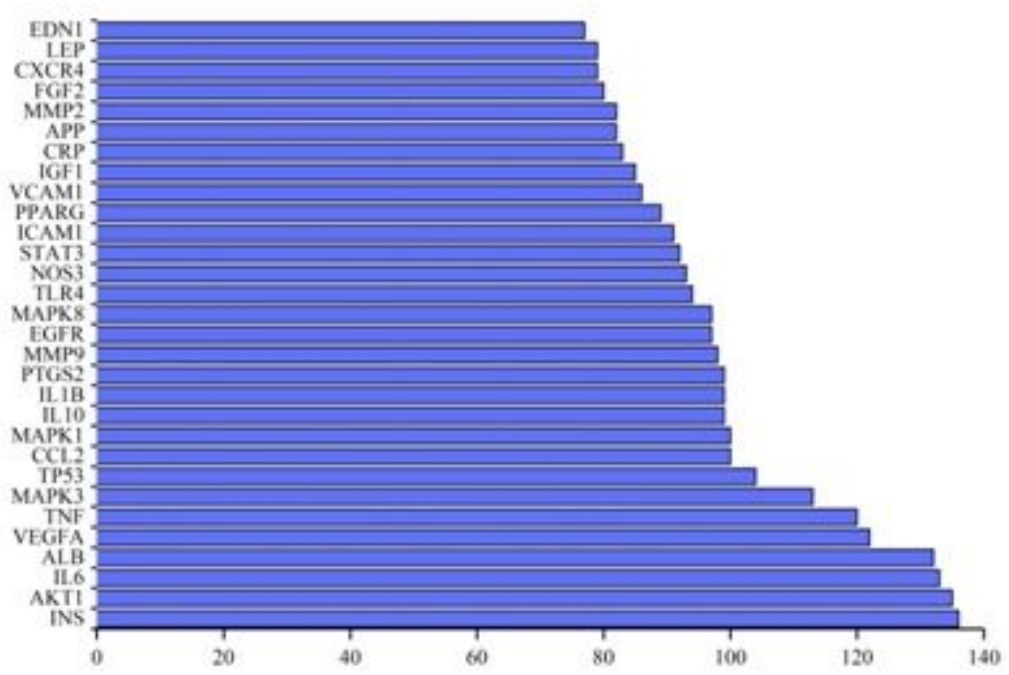

Figure 3

Maxing Shigan Decoction-key target of lung and heart injury 


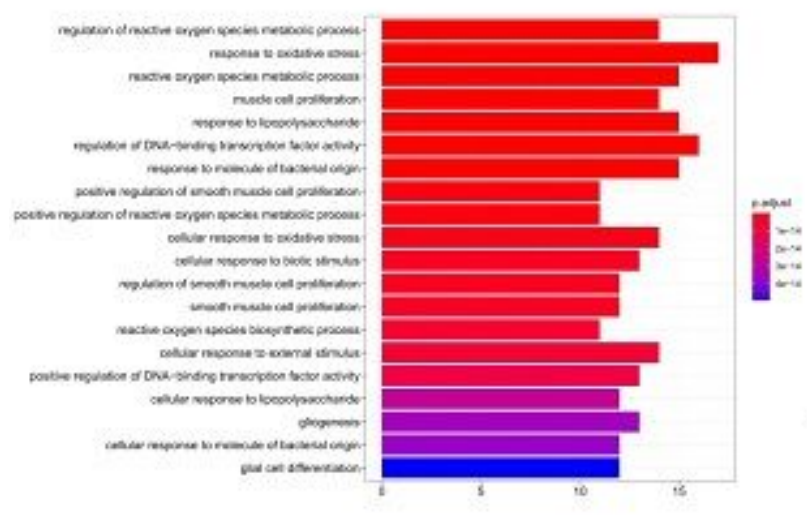

A

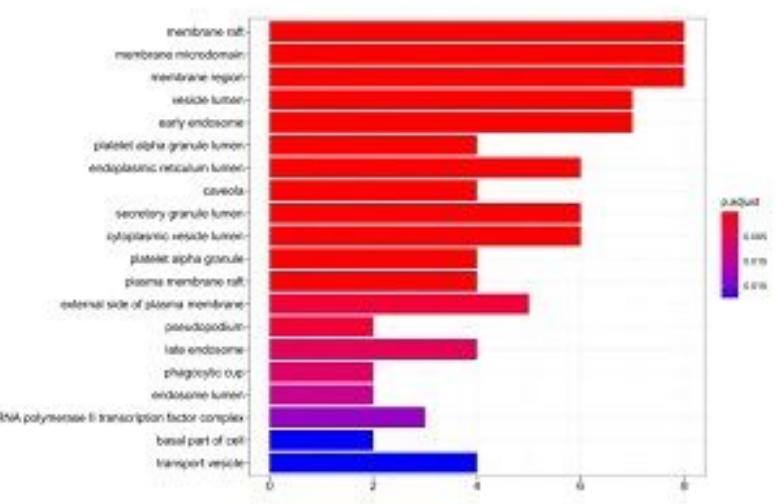

B

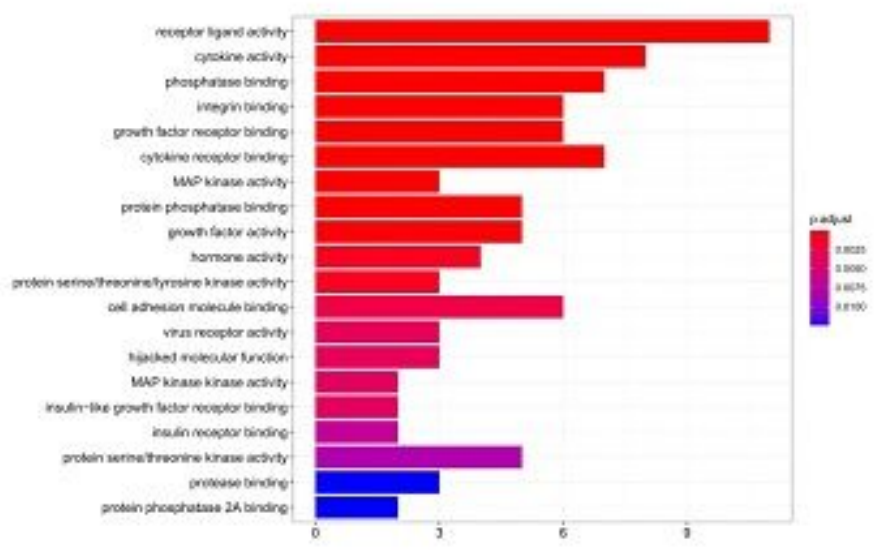

$\mathrm{C}$

Figure 4

GO enrichment analysis (A) Biological Process (B) Cell Composition (C) Molecular Function 


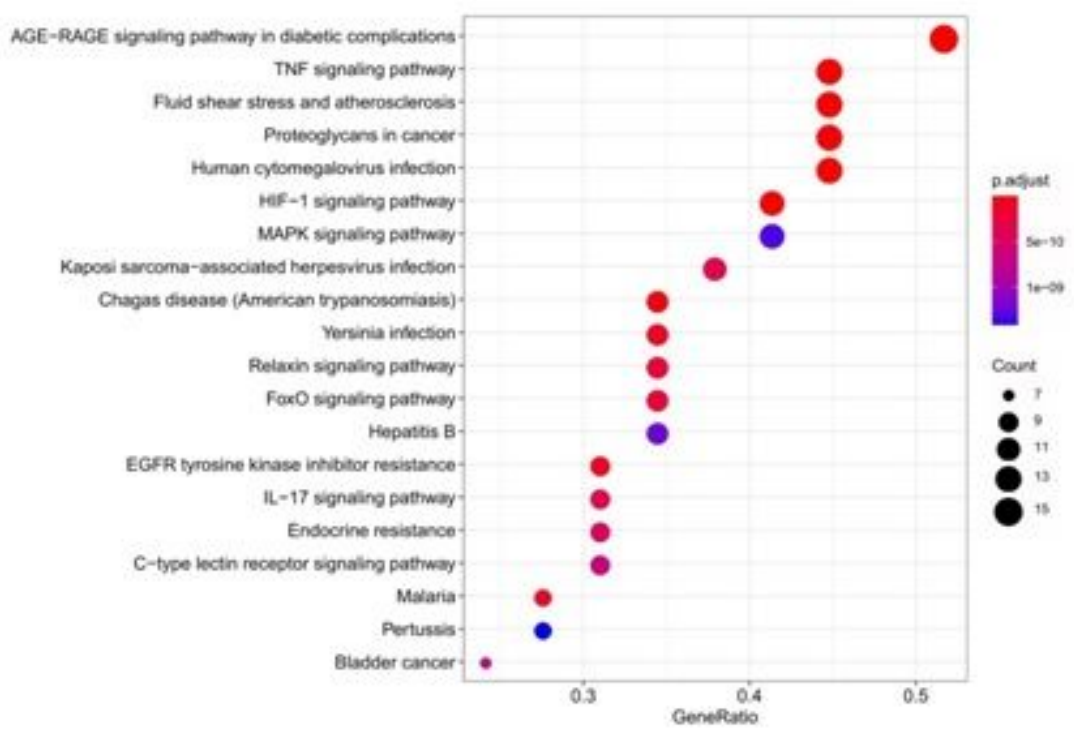

\section{Figure 5}

KEGG analysis bubble chart

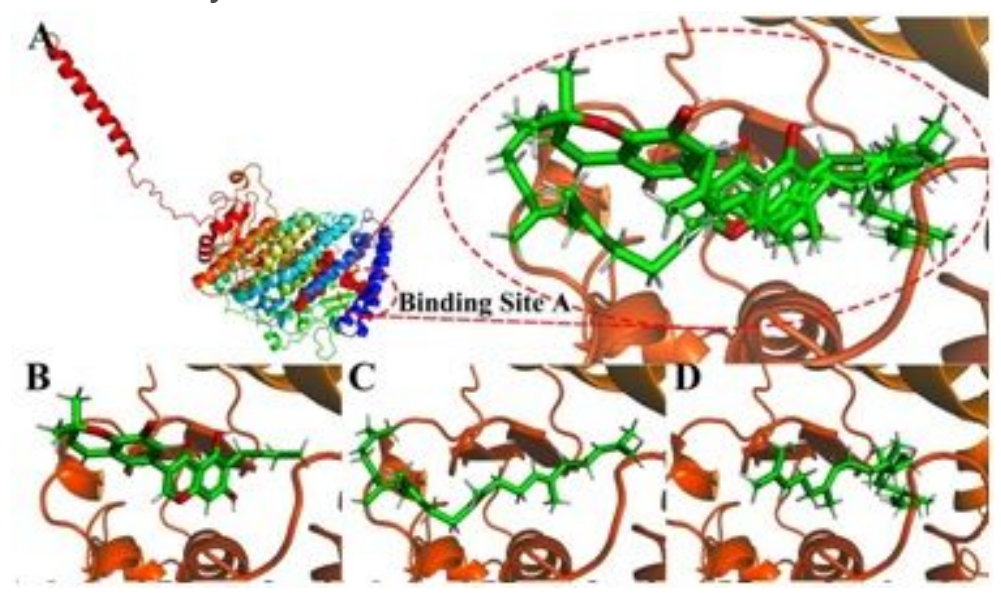

Figure 6

(A) The overall conformation display of the active ingredient docking with the A site of ACE2, (B) the docking model of Licorice-Gancaonin H-ACE2-A, (C) the docking model of Ephedra-Supraene-ACE2-A, (D) Almond- (6Z, 10E, 14E, 18E) -2, 6, 10, 15, 19, 23-hexamethyltetracosa-2, 6, 10, 14, 18, 22-hexaene-ACE2-A docking model. 


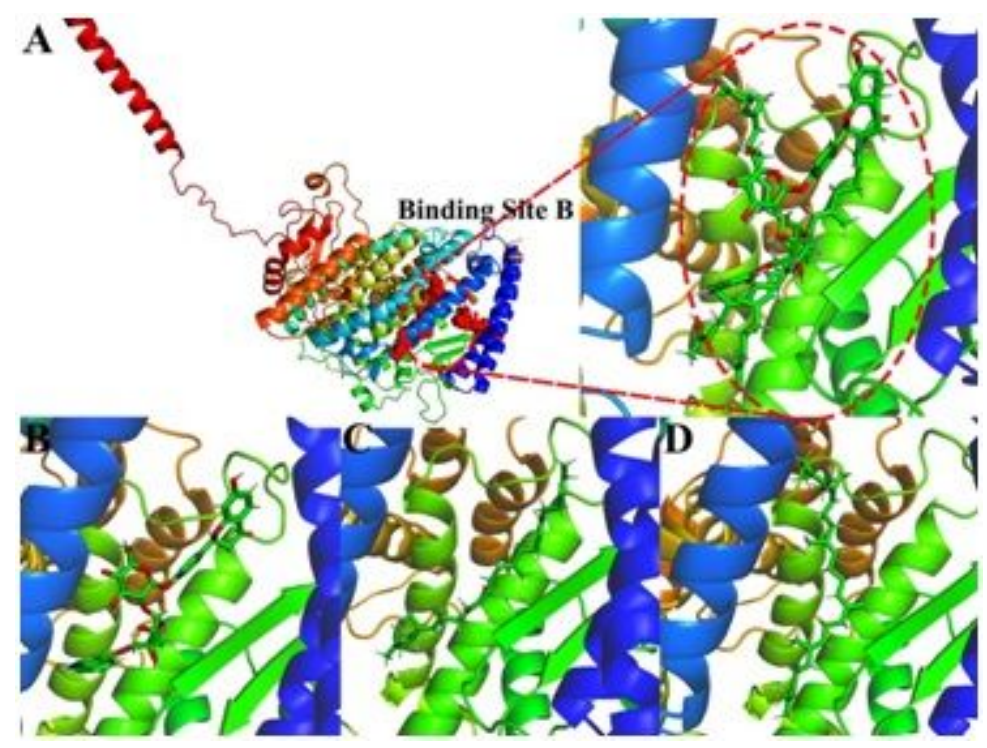

Figure 7

(A) The overall conformation display of the active ingredient and the ACE2 B site docking, (B) LicoriceLicorice Glycoside E-ACE2-B docking model, (C) Ephedra-Supraene-ACE2-B docking model, (D) Almond$(6 \mathrm{Z}, 10 \mathrm{E}, 14 \mathrm{E}, 18 \mathrm{E})-2,6,10,15,19,23$-hexamethyltetracosa-2, 6, 10, 14, 18, 22-hexaene-ACE2-B docking model.

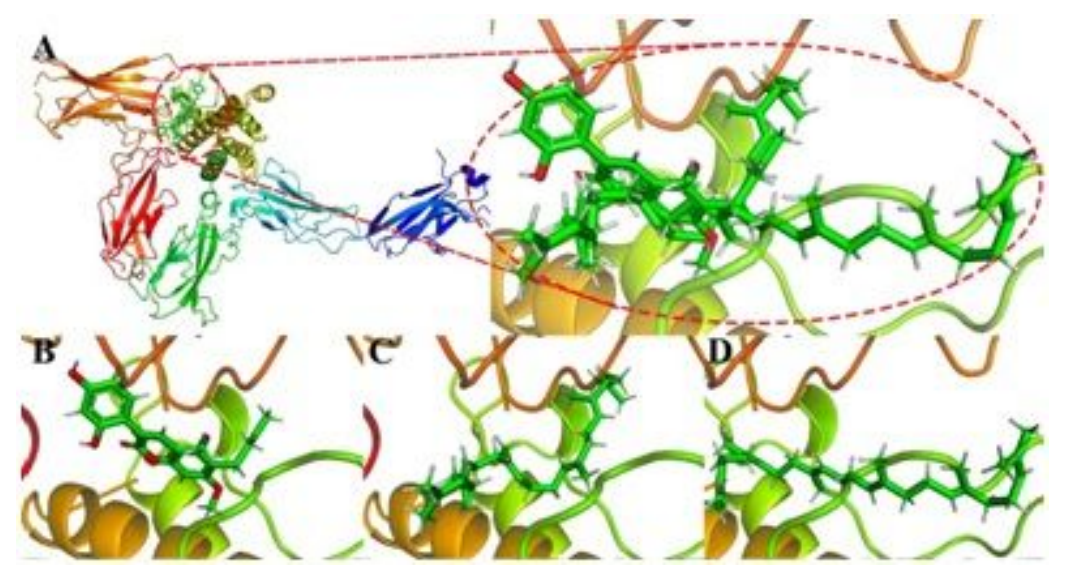

Figure 8

(A) Display of the docking binding site and overall binding conformation of the target IL 6 and the active ingredient, (B) Licorice-Glycyrin-IL6 docking model; (C) Ephedra-Supraene-IL6 docking model, (D) Almond$(6 Z, 10 \mathrm{E}, 14 \mathrm{E}, 18 \mathrm{E})-2,6,10,15,19,23$-hexamethyltetracosa-2, 6, 10, 14, 18, 22-hexaene- IL 6 docking model. 


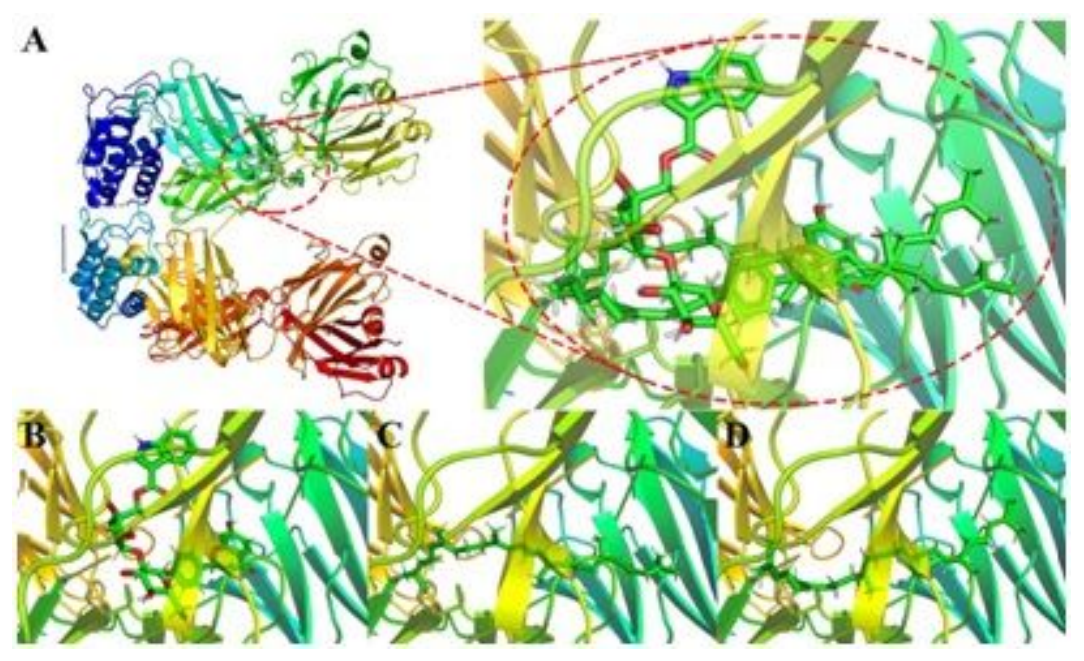

Figure 9

(A) Display of the docking binding site and overall binding conformation of the target GM-CSF and the active ingredient, (B) Licorice-Glycyrin-GM-CSF docking model, (C) Ephedra-Supraene-GM-CSF docking model; (D) Almond- (6Z, 10E, 14E, 18E)-2, 6, 10, 15, 19, 23-hexamethyltetracosa-2, 6, 10, 14, 18, 22 hexaene-GM-CSF docking model. 